University of Nebraska - Lincoln

DigitalCommons@University of Nebraska - Lincoln

U.S. Environmental Protection Agency Papers

U.S. Environmental Protection Agency

2002

Overview of the use of the the U.S. EPA exposure factors handbook

Jacqueline Moya

U.S. EPA, moya.jacqueline@epamail.epa.gov

Linda Phillips

Versar Inc.

Follow this and additional works at: https://digitalcommons.unl.edu/usepapapers

Moya, Jacqueline and Phillips, Linda, "Overview of the use of the the U.S. EPA exposure factors handbook" (2002). U.S. Environmental Protection Agency Papers. 173.

https://digitalcommons.unl.edu/usepapapers/173

This Article is brought to you for free and open access by the U.S. Environmental Protection Agency at DigitalCommons@University of Nebraska - Lincoln. It has been accepted for inclusion in U.S. Environmental Protection Agency Papers by an authorized administrator of DigitalCommons@University of Nebraska - Lincoln. 


\title{
Overview of the use of the U.S. EPA exposure factors handbook
}

\author{
Jacqueline Moyaa, Linda Phillips ${ }^{b}$ \\ a U.S. EPA, Washington DC, USA \\ b Versar Inc., Springfield, USA
}

Received September 10, 2001·Accepted November 7, 2001

\begin{abstract}
Risk assessments are important components of the decision making process. At hazardous waste sites, they are used as tools to determine appropriate cleanup levels. Therefore, it is critical that the best up-to-date methods, models, and exposure data are available to the exposure and risk assessor to realistically estimate the potential for human and ecological exposures to environmental contaminants. The EPA Exposure Factors Handbook published in 1997 is a tool available to exposure assessors which summarizes statistical data on exposure factors necessary to conduct human health exposure assessments. Since it was first published by EPA in 1989, the handbook has been the primary source of data for human exposure assessments. The purpose of this paper is to provide an overview of the handbook, its impact, applications, discussion about data gaps, and future directions.
\end{abstract}

Key words: Exposure factors - human exposures - food consumption

\section{Introduction}

The goal of the exposure factors handbook (EFH) is to (1) summarize data on human behaviors and characteristics which affect exposure to environmental contaminants, and (2) recommend values to use for these factors (U. S. EPA, 1997a). The EFH has become the primary source of human exposure factors data among exposure assessors. Its use has resulted in more consistency among exposure assessments conducted by the agency. Although the recommendations provided in the handbook are not legally binding on any EPA program office, many offices have adopted them in their exposure and risk assessments. For example, the Superfund office uses the handbook recommendations in their assessments of hazardous waste sites to determine appro- priate cleanup levels. The handbook is also used by the EPA Office of Solid Waste in support of their regulations. The Office of Pesticides used the recommendations in the handbook to derive default exposure factors in the 1997 Residential Standard Operating Procedures (SOPs) (U.S. EPA, 1997b). Although used widely by the agency, use of the EFH has not been limited to the EPA. It has had a wide application among exposure assessors in the United States and around the world. A quick search on the World Wide Web, resulted in numerous examples of the use of this handbook. For example, the American Medical Association used the handbook to estimate exposures to lead in burning candles (Sobel et al., 2000). The Handbook has also been used by States. For example, the New York Department of Health used it to address exposures associated with their

Corresponding author: Jacqueline Moya, U.S. Environmental Protection Agency (8623D), 1200 Pennsylvania Ave., Washington DC, 20460, USA. Phone: ++2025643245, Fax: ++2025650079,

E-mail: moya.jacqueline@epamail.epa.gov 
adult mosquito control programs (NYCDOH, 2000). International use of the handbook has also been reported. Health Canada developed their Ambient Air Quality Objectives for ground-level ozone using the recommendations in the handbook (Health Canada, 2000). The Harvard Institute for International Development under cooperative agreement with the U.S. Agency for International Development (USAID) used the handbook to estimate risks associated with particulate matter in an industrial city in southern Russia (Larson et al. 1998). The European community has also used the handbook as a model for the development of exposure factors sourcebook (Zaleski and Gephart, 2000). This document summarizes data similar to that of the $\mathrm{EFH}$, except that the data are specific to Europe.

Before the 1997 handbook was published, assessors relied in the $1989 \mathrm{EFH}$ for their exposure factors data. The 1989 handbook contained the food consumption data from the United States Department of Agriculture (USDA) Nationwide Food Consumption Survey (NFCS) 1977-78. Because consumption behavior has changed significantly over the years, the impact of the $1997 \mathrm{EFH}$ has been more significant in assessments involving exposure via the ingestion of contaminated foods. The 1997 handbook contains data from the 198991 Continuing Survey of Intake by Individuals (CSFII). Obtaining data that is up-to-date and reflects recent consumption habits is critical. Recently, EPA has conducted, and will be publishing, the analysis of the 1994-1996 CSFII data. Table 1 shows trends in food consumption over the years, including the results from the 1994-1996 CSFII survey. One can observe from this table that consumption of fruits and vegetables has increased significantly since 1977, while consumption of meat products has declined.

\section{Applications}

Exposure assessors are often asked to assess the exposure to individuals who live near contaminated sites and grow their own food. Foods can get contaminated via uptake of chemicals in the soil or water, or from the deposition of contaminants from air. Estimating exposures among these individuals requires data on the concentration of chemicals in the food item, home-produced intake rates, and the frequency and duration of exposure. The following example is intended to illustrate how to use the data from the EFH to construct a scenario and estimate exposure through this potential exposure pathway.

First, let's assume that the assessor is interested in the mean lifetime average daily dose from the ingestion of home-produced contaminated vegetables. Exposure via this pathway can be calculated using the following equation (U.S. EPA 1992):

$L A D D_{\text {POT veg ing }}=\frac{C_{\text {veg }} \times I R_{\text {veg }} \times E F \times E D}{A T}(1)$ where:

$\mathrm{LADD}_{\mathrm{POT} \text { veg ing }}=$ potential lifetime average daily dose from ingestion of contaminated vegetable $(\mathrm{mg} / \mathrm{kg}$-day)

$\mathrm{C}_{\mathrm{veg}}=$ concentration of contaminant in the homegrown vegetable from the site

$\mathrm{IR}_{\mathrm{veg}}=\quad$ per capita intake rate of vegetables homegrown at the site $(\mathrm{g} / \mathrm{kg}$ day)

$\mathrm{EF}=\quad$ exposure frequency (days/year)

$\mathrm{ED}=\quad$ exposure duration (years); and

$\mathrm{AT}=\quad$ averaging time (days)

It should be noted that the LADD equation above does not contain the body weight term in the

Table 1. Mean per capita consumption for major food categories.

\begin{tabular}{|c|c|c|c|c|}
\hline Food Item & NFCS $1977-78^{1}$ (g/day) & NFCS $1987-88^{2}$ (g/day) & CSFII $89-91^{2,3}$ (g/kg-day) & CSFII $94-96^{3,4}$ (g/kg-day) \\
\hline Total Vegetables & 201 & 182 & $\begin{array}{c}4.3 \\
258 \mathrm{~g} / \text { day }\end{array}$ & $\begin{array}{c}4.5 \\
270 \mathrm{~g} / \text { day }\end{array}$ \\
\hline Total Fruits & 142 & 142 & $\begin{array}{c}3.4 \\
204 \text { g/day }\end{array}$ & $\begin{array}{c}3.7 \\
222 \text { g/day }\end{array}$ \\
\hline Total Meats & 195 & 176 & $\begin{array}{c}2.1 \\
126 \mathrm{~g} / \text { day }\end{array}$ & $\begin{array}{c}2.1 \\
126 \mathrm{~g} / \text { day }\end{array}$ \\
\hline Total fish and shellfish & 12 & 11 & $\begin{array}{l}0.26 \mathrm{~g} / \mathrm{kg} \text {-day } \\
16 \mathrm{~g} / \mathrm{day}\end{array}$ & $\begin{array}{c}0.24 \\
14 \mathrm{~g} / \text { day }\end{array}$ \\
\hline Total Dairy & 308 & 258 & $\begin{array}{c}8.0 \\
480 \text { g/day }\end{array}$ & $\begin{array}{c}7.9 \\
474 \text { g/day }\end{array}$ \\
\hline
\end{tabular}

1 Pao et al., 1982

2 U.S. EPA, 1997a

${ }^{3} \mathrm{Grams} /$ day are estimated using the average body weight of $60 \mathrm{~kg}$, which is calculated using the number of survey respondents in each age category and their average

body weight among age groups.

${ }^{4}$ Versar, 2000 draft report titled CSFII Analysis of Food Intake Distributions, prepared under contract with EPA/NCEA, May 2000. 
denominator. This term is not necessary because intake rates are presented on a body weight basis in the EFH. For example, the variable IR ${ }_{\text {veg }}$ is expressed as intake per kilogram of body weight. This approach addresses any correlations that may exist between intake rate and body weight.

The derivation of appropriate intake rate values is essential to the proper characterization of exposure due to ingestion of contaminated home-produced vegetables. Because the derivation of these values require some data manipulation and an understanding of the data and their limitations, the discussion below will focus on how to derive an appropriate intake rate $\left(\mathrm{IR}_{\mathrm{veg}}\right)$.

Volume II of the EFH presents intake data for a variety of foods. The primary sources of information on food intakes come from the USDA NFCS and the USDA CSFII, which are briefly described here. A more detailed discussion about both of these surveys can be found in the EFH. Until 1988, USDA conducted the NFCS every 10 years to analyze the food consumption behavior and dietary status of Americans (USDA, 1992). In 1987-1988, there were two components of the NFCS. The household component collected information based on a recall of food used over a seven-day period. The term "used" refers to the consumption of food in the economic sense. The survey collected data on the amount of food that was brought into the house and available for consumption. In reality, some of the food may have not been consumed. Some food could have been discarded (e.g., inedible parts, spoiled) or fed to pets. The survey included information on the socioeconomic and demographic characteristics of households, and the types, amount, value, and sources of foods that were brought into the household and available for consumption (USDA, 1994). An important and unique aspect of this survey is that respondents identified if the food was purchased, home produced, or provided as a gift. Although USDA has conducted food consumption surveys in recent years, they do not include information on home produced foods. The EPA conducted analysis of these data to estimate consumption of homeproduced food items. These analyses are presented in the 1997 EFH. USDA also conducts the CSFII to assess food consumption behavior, nutritional content of diets, and knowledge and attitude about dietary guidance and health. The CSFII has been conducted three times: 1985 - 86 ( 2 years); 1989 91 (3 years); and $1994-96$ (3 years). The $1997 \mathrm{EFH}$ presents an analysis of food consumption data, based on the 1989-1991 CSFII. Since the handbook was published in 1997, the 1994-96 and 1998 CSFII, popularly known as "What We Eat in
America," have become available. EPA has recently analyzed the 1994-96 data to provide updates to the handbook, these are currently undergoing peer review. Therefore, for the purpose of this example, the 1989-91 data are used.

In the handbook, per capita intake rates are estimated using the entire population surveyed (i.e., consumers and non consumers). The term "consumers only intake rate" is used in the handbook to represent food consumption among those individuals reporting consuming the food item during the survey period (i.e, not including individuals with zero consumption). The consumers only intake rate will be higher than the per capita intake. In this example, the per capita intake rate for homegrown vegetables $\left(\mathrm{IR}_{\mathrm{veg}}\right)$ can be estimated from data in the $1997 \mathrm{EFH}$ using two slightly different, but equally appropriate, approaches. In the first approach, the mean per capita ("as eaten”) vegetable intake rate (based on the 1989/91 CSFII individual intake analysis) for all individuals $(4.3 \mathrm{~g} /$ kg-day) from Table 9-4 in the EFH, is multiplied by the fraction of total vegetable intake represented by homegrown vegetables (0.07) from Table 13-71, based on the NFCS household consumption analysis (U.S. EPA 1997a). The resulting value represents the per capita homegrown intake rate $(0.29 \mathrm{~g} / \mathrm{kg}$-day). In the second approach, the mean "consumer only" homegrown intake rate $(2.1 \mathrm{~g} / \mathrm{kg}$-day $)$ from Table 13-13, based on the NFCS household consumption analysis, is multiplied by the percent of individuals consuming homegrown vegetables during the survey period $(0.18)$ from Table 13-13 to get the per capita homegrown vegetable intake rate $(0.38 \mathrm{~g} / \mathrm{kg}$ day) (U. S. EPA 1997a). Also, because the intake data used here are based on household use data (i. e., they are based on the amount of food brought into the home in "raw" form; they are not "as eaten" intake rates such as those used above in approach 1), they are multiplied by 1 minus the weight of the food item lost in preparation (Table 13-7) to arrive at the per capita "as eaten" homegrown vegetable intake rate (U.S. EPA 1997a). Because there is no preparation loss value for total vegetables, a mean preparation loss value from data for 17 different vegetables presented in Table 13-7 of the EFH is used here $(0.12$ or 12 percent) (U.S. EPA 1997a). The resulting value $[2.1 \mathrm{~g} / \mathrm{kg}$-day $* 0.18 *(1-0.12)]$ represents the per capita homegrown intake rate $(0.33 \mathrm{~g} / \mathrm{kg}$-day $)$. The $\mathrm{IR}_{\mathrm{veg}}$ values calculated by these two approaches are very similar, with the intake rate from the second approach being slightly higher. The second approach uses data from the household portion of the NFCS in which waste and spoilage are not considered in calculating intake rates. This may account for 
the slightly higher value. However, the difference between 0.29 and 0.33 is probably not significant enough to result in a major impact in estimated exposures.

Assuming that the mean concentration of the chemical found in all the vegetables $\left(C_{\text {veg }}\right)$ was $1 \mathrm{E}$ $3 \mathrm{mg} / \mathrm{g}$ (i.e., $1 \mathrm{ppb}$ ); assuming an exposure frequency $(E F)$ of 365 days a year; an exposure duration (ED) of 9 years, based on the $50^{\text {th }}$ percentile residence time (U.S. EPA 1997a); and an averaging time of 75 years (U.S. EPA 1997a), LADD ${ }_{\text {POT veg ing is }}$ calculated using approach 1 and approach 2 for deriving $\mathrm{IR}_{\mathrm{veg}}$. The $\mathrm{LADD} \mathrm{POT}_{\mathrm{Peg} \text { ing }}$ using approach 1 and 2 are $3.5 \times 10^{-5} \mathrm{mg} / \mathrm{kg}$-day and $4.0 \times 10^{-5} \mathrm{mg} /$ $\mathrm{kg}$-day, respectively. These doses are very similar because the values used for intake rates are very similar, as explained above. Assuming that the chemical of interest is a carcinogen, risks can be calculated by multiplying the $\mathrm{LADD}_{\mathrm{POT} \text { veg ing }}$ times the cancer potency factor.

The example presented here is used to represent central tendency exposures from the consumption of home-produced vegetables among the general population. Exposure to consumers-only of homeproduced vegetables can be estimated using approach 2 only. The reason is that the fraction of the total vegetable intake that is home-produced used in approach 1 (i.e., .07) represents the fraction among all the respondents to the survey, not just the consumers. This fraction would be different for the population of consumers only.

The uncertainties associated with this example scenario are related to assumed activity patterns of the receptor population and the input parameters used. Implicit in this scenario is the assumption that the population of interest actually consumes produce grown on site, and that consumption occurs at the rates specified in the handbook. Also because rates for intake of total vegetables are used, and a single value is used to represent the concentration of contaminant in vegetables, it is assumed that all vegetables consumed from the site contain contaminant at the average. The intake rates used in this example are based on survey data collected over short periods (i.e., 3 to 7 days), but are used to represent long-term averages. The EFH describes the uncertainty associated with this assumption, and concludes that for broad food categories such as total vegetables, the short-term distribution may be a reasonable approximation of the long-term distribution of average daily intakes, but may overestimate the upper percentiles of the long-term distribution (U.S. EPA 1997a). Thus, use of the data from the upper end of the intake distribution is likely to be quite conservative.

\section{Discussion}

The data in the Exposure Factors Handbook come from a variety of sources. The data were summarized from studies published in the peer-reviewed scientific literature and final government reports. Criteria for the selection and evaluation of studies were developed to ensure that the data included were of known quality. The EFH was a pioneer in developing such criteria for the use of secondary data. The criteria evaluated the following elements: level of peer review, accessible data, reproducible data/ results, focus on the factor of interest, data pertinent to the U.S. population, focus on primary data, currency of data, adequacy of data collection period, validity of approach for collecting the data, representativeness of the study population, characterization of variability of the population, minimal bias in study design, and minimal uncertainty in the data. These elements and professional judgement were used to provide a confidence level on each one of the recommendations presented in the handbook. Limitations of the data are also discussed for each recommended value.

The need for the most up-to-date and accurate data on exposure factors used in assessing exposure to contaminants in the environment is of high priority to exposure assessors throughout the U.S. The development of the latest version of the EFH brought to light the need for a more comprehensive program that addresses issues related to exposure factors. The completion of the EFH has only been the first step in fulfilling this need. The EFH should be a living document where chapters and recommendations are updated as new data are available. In addition, many data needs have been identified and follow-up research is underway to address some of the data gaps. Some examples of data gaps include:

- better and more recent estimates of home production and consumption of home-grown or home-produced foods

- exposure factors data and information on occupational exposures

- fish consumption estimates for subsistence fishermen

- soil intake rates for adults

- improve estimates of soil intake rates for children, as well as soil adherence factors and prevalence of pica behavior

- derive a methodology to extrapolate from shortterm data to long-term or chronic exposures

- incidence of breast feeding and better estimates of breast milk intake rates 
- better characterization of children's behavior and use of consumer products

A web page has been created under the EPA home page (http://www.epa.gov/ncea/jmprog.htm) to serve as a focal point where the most current information and data on exposure factors can be found. This web site provides a guide to the most current literature, status reports on NCEA projects aimed at improving the state-of-knowledge on exposure factors, and links to other sites where exposure factors related data can be found. The web page will allow NCEA to update and post recommendations for a particular exposure factor when enough data on that factor are available and after the appropriate level of peer review has been completed without having to reissue a new document.

\section{Disclaimer}

The views expressed in this paper are those of the authors and do not necessarily reflect the views or policies of the U.S. Environmental Protection Agency.

\section{References}

Health Canada, 2000: National Ambient Air Quality Objectives for Ground Level Ozone, June 20, 2000.

Larson, B. A., Avaliani, S., Golub, A., Rosen, S., Shaposhnikov, D., Stukova, E., and Wolff, S.: The Economics of Air Pollution Health Risk in Russia: A Case Study of Volgograd, Environment Discussion Paper No. 38, NIS-EEP PROJECT, January 1998.

NYCDOH, 2000: Adult Mosquito Control Program, Draft Environmental Impact Statement, Final Scope of Analysis, New York City Department of Health, December 20, 2000.

http://www.ci.nyc.ny.us/html/doh/pdf/wnv/finals.pdf
Pao, E. M., Fleming, K. H., Guenther, P. M., Mickle, S. J.: Foods Commonly Eaten by Individuals: Amount Per Day and Per Eating Occasion, Consumer Nutrition Center, Human Nutrition Information Service, U.S. Department of Agriculture, Hyattsville, MD, Home Economics Research Report Number 44, March 1982.

Sobel H. L., Lurie, P., Wolfe, S. M.: Research Letters: Lead Exposure from Candles, JAMA Vol 284, No. 2, July 12, 2000. (http://jama.ama-assn.org/issues/ v284n2/ffull/jlt0712-6.h tml)

U.S. EPA, 1992: Guidelines for Exposure Assessments, Office of Health and Environmental Assessment, Office of Research and Development. EPA/600Z-92/ 001. FR 57: 22888-22938.

U.S. EPA, 1997a: Exposure Factors Handbook, National Center for Environmental Assessment, Office of Research and Development, EPA/600/P-95/002Fa-c.

U.S. EPA, 1997b: Scientific Advisory Panel (SAP) September 1997 Meeting Standard Operating Procedures (SOPs) for Residential Exposure Assessments, Office of Science Coordination Policy. http://www. epa.gov/oscpmont/sap/1997/september/sopindex.htm

USDA, 1992: Changes in food consumption and expenditures in American households during the 1980's. U.S. Department of Agriculture. Washington, D.C. Statistical Bulletin No. 849.

USDA, 1993: Food and nutrient intakes by individuals in the United States, 1 Day, 1987-88. Nationwide Food Consumption Survey 1987-88, NFCS Report No. 87-I-1.

USDA, 1994: Food consumption and dietary levels of households in the United States, 1987-88. U.S. Department of Agriculture, Agricultural Research Service.

Report No. 87-H-1.

Zaleski, R. and Gephart, L.: Exposure Factors Sourcebook for European Populations, with Focus on UK Data, NICOLE Exposure Factors Project Sponsored by ExxonMobil, ICI, and Shell ExxonMobil Biomedical Sciences Inc., May 2000. 